\title{
Parathyroid Carcinoma and Adenoma Co-existing in One Patient: Case Report and Comparative Proteomic Analysis
}

\author{
FEDERICA CIREGIA ${ }^{1,2}$, FILOMENA CETANI ${ }^{1}$, ELENA PARDI $^{1}$, ALESSIO SOGGIU $^{3}$, CRISTIAN PIRAS $^{4}$, \\ LORENZO ZALLOCCO ${ }^{5}$, SIMONA BORSARI ${ }^{1}$, MAURIZIO RONCI ${ }^{6}$, VANNI CARUSO ${ }^{7}$, \\ CLAUDIO MARCOCCI ${ }^{1}$, MARIA ROSA MAZZONI ${ }^{5}$, ANTONIO LUCACCHINI ${ }^{1}$ and LAURA GIUSTI ${ }^{8}$ \\ ${ }^{1}$ Department of Clinical and Experimental Medicine, University of Pisa, Pisa, Italy; \\ ${ }^{2}$ Department of Rheumatology, GIGA Research, \\ Centre Hospitalier Universitaire (CHU) de Liège, University of Liège, Liège, Belgium; \\ ${ }^{3}$ Surgical and Dental Sciences-One Health Unit, Department of Biomedical, University of Milano, Milan, Italy; \\ ${ }^{4}$ Department of Health Sciences, Campus Universitario "S. Venuta", \\ University "Magna Gracia" of Catanzaro, Catanzaro, Italy; \\ ${ }^{5}$ Department of Pharmacy, University of Pisa, Pisa, Italy; \\ ${ }^{6}$ Department of Pharmacy, University G. d'Annunzio of Chieti-Pescara, Chieti, Italy; \\ ${ }^{7}$ School of Pharmacy \& Pharmacology - College of Health and Medicine, \\ University of Tasmania, Hobart, TAS, Australia; \\ ${ }^{8}$ School of Pharmacy, University of Camerino, Camerino, Italy
}

\begin{abstract}
Background/Aim: The lack of specific parathyroid carcinoma $(P C)$ biomarkers in clinical practice points out the importance of analyzing the proteomic signature of this cancer. We performed a comparative proteomic analysis of $P C$ and parathyroid adenoma (PA) co-existing in the same patient. Patients and Methods: $P C$ and PA were taken from a 63-year-old patient. Using two-dimensional differential gel electrophoresis (2D-DIGE) coupled to mass spectrometry we examined the differences between $P C$ and PA proteins. For validation, additional $P C$ and $P A$ samples were obtained from 10 patients. Western blot analysis was used to validate the difference of expression observed with 2D-DIGE analysis. Bioinfomatic analysis was performed using QIAGEN's Ingenuity Pathways Analysis (IPA) to determine the predominant canonical pathways and interaction networks involved. Results: Thirty-three differentially expressed proteins were identified in PC compared to PA. Among these,
\end{abstract}

This article is freely accessible online.

Correspondence to: Dr. Laura Giusti, School of Pharmacy, University of Camerino, Via Gentile III da Varano, 62032 Camerino, Italy. Tel: +39 0737402916, Fax: +39 0737402457, email: laura.giusti@unicam.it

Key Words: Parathyroid carcinoma, parathyroid adenoma, 2DDIGE, proteomics, biomarkers, case report. ubiquitin C-terminal hydrolase-L1 (UCH-L1) was highly overexpressed in PC. The result was confirmed by Western Blot analysis in additional PC samples. Conclusion: Our comparative proteomic analysis of co-existing neoplasms allowed detecting specific and peculiar differences between $P C$ and PA overcoming population biological variability.

Primary hyperparathyroidism (PHPT) is an endocrine disease characterized by excessive parathyroid hormone (PTH) secretion and hypercalcemia. Approximately $85 \%$ of the patients have a single parathyroid adenoma (PA), 10\% hyperplasia and 3\% double adenoma. In contrast, atypical PA and parathyroid carcinoma (PC) are rarer, being the latter the rarest parathyroid tumor $(<1 \%)(1,2)$. Most parathyroid tumors are sporadic, although approximately 5$10 \%$ are associated to familial syndromes, namely multiple endocrine neoplasia (MEN) types 1, 2A, and 4, hyperparathyroidism-jaw tumor syndrome (HPT-JT) and familial isolated hyperparathyroidism (FIHP) (3). The majority of PCs have an indolent course and the most frequent clinical manifestations, due to PTH-related hypercalcemia, are similar, but more severe, to those of the benign counterpart (4).

On the sole basis of clinical signs, diagnosis of PC can be difficult and is usually made postoperatively at histology. In some cases, the distinction between PC and atypical PA can be challenging. Of note, atypical PA represents an intermediate form of parathyroid neoplasm 
with uncertain malignant potential presenting histological features (i.e. solid growth pattern, fibrous bands and cellular atypia) common to PC. At variance with PC, atypical PA lacks evident signs of local invasion and/or metastasis $(2,4)$.

The pathogenic mechanisms and gene dysfunctions underlying sporadic PHPT development are still unknown in about half of cases, although in recent years several studies have associated different genetic aberrations to sporadic PAs or PCs $(2,5)$. Rearrangement or overexpression of the cyclin D1 (CCND1) gene can occur in $20-40 \%$ of sporadic PAs (6), while somatic mutations of the MEN1 gene, encoding menin, are detected in $12-35 \%(7,8)$. Rare somatic mutations of other genes have also been implicated in a small percentage of sporadic PAs (5). Mutations of the tumor suppressor cell division cycle 73 (CDC73) gene, which encodes parafibromin, are responsible for hereditary HPT-JT and up to $70 \%$ of sporadic PCs $(2,9)$. Recently, whole exome sequencing has confirmed the prevalence of CDC73 mutations in PCs but also highlighted other genetic aberrations mainly implicated in cancer-related pathways (2). Truncating mutations are the most frequent CDC73 aberrations predicting either the lack or reduction of parafibromin expression. Parafibromin immunostaining has been proposed as a diagnostic tool to differentiate PCs from PAs since diffuse or focal loss of the protein has been frequently detected in the former but very rarely in the latter tumors (9). Other immunohistochemical markers have been suggested but none has the desirable sensitivity and specificity for the differential diagnosis of PC (9). The lack of specific PC biomarkers in clinical practice points out the importance of analyzing the proteomic signature of this cancer to better comprehend the protein networks involved in PC pathogenesis. However, such deep study is made difficult by the rarity of this cancer. Since 2011, when Giusti et al. (10) firstly used a proteomic approach to analyze the total protein expression of PAs compared to normal parathyroid tissues, other authors have investigated the proteomic profile of PAs and parathyroid hyperplastic tissues (11-13). The characterization of the proteomic signature of PA could represent a useful starting point for a comparative analysis with the proteome of PC.

In the present study, using an approach based on twodimensional electrophoresis (2DE) coupled to mass spectrometry (MS), we performed a comparative proteomic analysis to examine the global differences of protein profile between a PC and a PA co-existing in the same patient, an extremely rare clinical condition. This intra-individual comparison represented a unique and useful opportunity, which allowed us to reveal distinctive PC protein features without any hindrance due to differences among patients such as age, sex, genetic background, life style and environmental factors.

\section{Patients and Methods}

Case report. A 63-year-old man was referred to our Clinic in July 2007 for persistent PHPT. The clinical history was notable for recurrent nephrolithiasis. In 2004, at the age of 59 years, severe PHPT was diagnosed by marked hypercalcemia (serum calcium 15 $\mathrm{mg} / \mathrm{dl}$ ) and markedly elevated PTH levels $(>1,000 \mathrm{pg} / \mathrm{ml})$. One month later he was submitted to surgery with the removal of a $4-\mathrm{cm}$ enlarged lower left parathyroid. There was no mention of local invasion in the surgical report. The histological diagnosis was consistent with atypical PA. A persistent PHPT was evident after surgery. At the time of our observation, serum calcium and PTH were mildly elevated $(10.7 \mathrm{mg} / \mathrm{dl}$ and $115 \mathrm{pg} / \mathrm{ml}$, respectively). Neck ultrasound did not show a parathyroid lesion. Computed tomography (CT) showed the presence of a left 9-mm and an inferior right 4-mm parathyroid lesion. Therefore, surveillance was advised. During follow-up, serum calcium and PTH progressively increased up to $13.8 \mathrm{mg} / \mathrm{dl}$ and $361 \mathrm{pg} / \mathrm{ml}$, respectively. Neck ultrasound and CT displayed a $3.5 \mathrm{~cm}$ cervico-mediastinal parathyroid lump. Abdomen CT excluded kidney stones and detected multiple millimetric pancreatic lesions. Neuroendocrine markers were in the normal range. In July 2014, the patient underwent an en bloc resection of the cervico-mediastinal mass, left thyroid lobe, central lymph nodes and lower right parathyroid gland. No sign of local invasion was evident at neck exploration. Histology showed a PC infiltrating the left thyroid lobe and the nearby tissues, metastatic lymph nodes of central compartment, whereas the lower right parathyroid exhibited signs of hyperplasia. Immunohistochemical staining showed that PC was positive for chromogranin A but negative for thyroglobulin and thyroid transcription factor 1 (TTF1). In addition, histology revealed two small papillary thyroid carcinomas. After surgery, a persistence of PHPT was still evident. Imaging studies excluded residual tumoral parathyroid tissue in the left side and showed the presence of an additional inferior right enlarged parathyroid gland. Therefore, 4 months later, the patient underwent surgical removal of the lower right parathyroid and histology revealed a chief cell PA.

Taking into account the presence of multiple parathyroid and thyroid tumors, adrenal gland hyperplasia and suspicious pancreatic neuroendocrine microlesions, MEN1 or MEN4 syndromes were suspected. However, no germline mutations of MEN1, cyclin dependent kinase inhibitor 1B (CDKN1B) and CDC73 genes were detected. During follow-up, the patient showed normocalcemia and no evidence of disease recurrence or metastasis. For proteomic analysis, PC and PA samples were immediately snap frozen in liquid nitrogen and stored at $-80^{\circ} \mathrm{C}$ until use

Patients for validation. Additional $\mathrm{PC}$ and $\mathrm{PA}$ samples were obtained from 10 patients (5 PA and 5 PC), whose clinical and biochemical characteristics are shown in Table I. All tissue samples were collected during surgery, immediately snap frozen in liquid nitrogen and stored at $-80^{\circ} \mathrm{C}$ until use.

Ethics statements. The research was carried out according to the guidelines of the Declaration of Helsinki, and the Local Ethics Committee (Comitato per la Sperimentazione Clinica dei Farmaci, Azienda Ospedaliera Universitaria Pisana) approved the study, and the patients gave written informed consent for the inclusion in the study.

Protein extraction. Frozen parathyroid tissues were suspended with lysis buffer (30 mM Tris, $7 \mathrm{M}$ urea, $2 \mathrm{M}$ thiourea, 4\% CHAPS, $\mathrm{pH}$ 
Table I. Clinical and biochemical data of patients with parathyroid carcinoma and parathyroid adenoma used in validation experiments.

\begin{tabular}{|c|c|c|c|c|c|c|}
\hline ID & Gender & $\begin{array}{l}\text { Age at diagnosis } \\
\text { (years) }\end{array}$ & $\begin{array}{l}\text { Ionized calcium } \\
(\mathrm{mmol} / \mathrm{l})\end{array}$ & $\begin{array}{l}\text { PTH } \\
(\mathrm{pg} / \mathrm{ml})\end{array}$ & $\begin{array}{l}\text { 25-hydroxyvitamin D } \\
(\mathrm{ng} / \mathrm{ml})\end{array}$ & $\begin{array}{c}\text { Clinical } \\
\text { manifestations }\end{array}$ \\
\hline \multicolumn{7}{|c|}{ Parathyroid adenoma } \\
\hline 1 & $\mathrm{~F}$ & 60 & 1.9 & 322 & 33.8 & $\begin{array}{l}\text { Osteoporosis } \\
\text { Nephrolithiasis }\end{array}$ \\
\hline 2 & $\mathrm{~F}$ & 62 & 1.4 & 178 & 17.8 & $\begin{array}{l}\text { Osteoporosis } \\
\text { Nephrolithiasis }\end{array}$ \\
\hline 3 & $\mathrm{~F}$ & 49 & 1.6 & 234 & 7.8 & Osteoporosis \\
\hline 4 & $\mathrm{~F}$ & NA & NA & NA & NA & NA \\
\hline 5 & $\mathrm{~F}$ & NA & NA & NA & NA & NA \\
\hline \multicolumn{7}{|c|}{ Parathyroid carcinoma } \\
\hline 6 & M & 62 & 1.8 & 384 & NA & Nephrolithiasis \\
\hline 7 & M & 45 & NA & NA & NA & NA \\
\hline 8 & $\mathrm{~F}$ & 58 & 1.8 & 640 & 9.2 & $\begin{array}{c}\text { Osteoporosis } \\
\text { Nephrolithiasis }\end{array}$ \\
\hline 9 & M & 53 & 1.6 & 444 & NA & $\begin{array}{l}\text { Osteoporosis } \\
\text { Nephrolithiasis }\end{array}$ \\
\hline 10 & $\mathrm{~F}$ & 43 & 1.8 & 501 & NA & $\begin{array}{l}\text { Osteoporosis } \\
\text { Nephrolithiasis }\end{array}$ \\
\hline
\end{tabular}

PTH: Parathyroid hormone; F: female; M: male; NA: not available. Normal ranges: Ionized calcium=1.13-1.32 mmol/1; PTH=10-65 pg/ml; 25hydroxyvitamin D: $\leq 10 \mathrm{ng} / \mathrm{ml}$ deficiency, $10-30 \mathrm{ng} / \mathrm{ml}$ insufficiency, $>150 \mathrm{ng} / \mathrm{ml}$ toxicity.

8.5). Tissues were sonicated $4 \mathrm{~s} \times 6$ times and subsequently transferred on a pre-cooled potter for the homogenization on ice. After incubation for $30 \mathrm{~min}$ at room temperature, the homogenate was centrifuged at $16,000 \times g$ for 10 min to remove undissolved material. Protein concentration was determined using the RC-DC Protein Assay (BioRad, Hercules, CA, USA) and bovine serum albumin was used as standard.

Two-dimensional differential in-gel electrophoresis (2D-DIGE). The dilution of samples with lysis buffer was adapted to have the same concentration for both tumor samples. The $\mathrm{pH}$ of samples was adjusted with $\mathrm{NaOH}$ to reach a value of 8.6. Cyanine dyes (CyDye) (GE Healthcare, Little Chalfont, Buckinghamshire, UK) were reconstituted in dimethylformamide and, before to perform the DIGE experiment, the binding between CyDye and the samples was verified by a labeling test. For this purpose, samples were pooled (total $25 \mu \mathrm{g})$ and labeled with CyDye $2(1 \mu \mathrm{g}$ proteins $/ 8$ pmol CyDye) and lysine $10 \mathrm{mM}$ (same volume of the dye). Proteins in the sample were separated on 7\% SDS-PAGE gels. After verifying binding of the samples with CyDye, 2D-DIGE was performed.

Forty $\mu \mathrm{g}$ of proteins from each sample were labeled with 320 pmol of Cy3 or Cy5. The internal standard was a pool of equal amounts of the two samples and was labeled with Cy2. A total of 3 gels were run, each gel contained $120 \mu \mathrm{g}$ of proteins: $40 \mu \mathrm{g}$ of adenoma (Cy5), $40 \mu \mathrm{g}$ of carcinoma (Cy3) and $40 \mu \mathrm{g}$ of the internal standard (Cy2). Lysine $10 \mathrm{mM}$ was added at the same volume as the CyDye. These labelled pooled samples were prepared for $2 \mathrm{D}$ by adding $0.5 \%$ immobilized $\mathrm{pH}$ gradient buffer and $34 \mathrm{mM}$ dithiothreitol (DTT), and then incubated for $20 \mathrm{~min}$ to promote reduction. Isoelectrofocusing (IEF) was performed using $18 \mathrm{~cm}$ Immobiline Dry Strips (BioRad) with a nonlinear pH 3-10 gradient.
IEF was carried on the PROTEAN ${ }^{\circledR}{ }^{1} 12^{\mathrm{TM}}$ IEF System (BioRad). After IEF, the strips were equilibrated during two steps of $15 \mathrm{~min}$ each in equilibration buffer ( $0.05 \mathrm{M}$ Tris, $6 \mathrm{M}$ urea, 2\% SDS, $20 \%$ glycerol) with $1 \%$ DTT in the first incubation or $2.5 \%$ iodoacetamide in the second one. The subsequent electrophoresis was performed on $12.5 \%$ SDS-PAGE gels with the EttanDALTsix electrophoresis unit (GE Healthcare Europe, Uppsala, Sweden) at a constant power of $1.5 \mathrm{~W} / \mathrm{gel}$. Gel images were acquired with a Typhoon apparatus (GE Healthcare Europe) following manufacturer protocol and analyzed using the 2D-DIGE module of the SameSpots v4.1 software (TotalLab; Newcastle Upon Tyne, UK). Statistical analysis was based on the normalized volume of each spot calculated by the software. Briefly, a total of 9 images, three technical replicates of PC, PA and internal standard, were aligned in a two stage process where each sample image was aligned to its internal standard (Cy2) and each internal standard image was aligned to the overall reference image (the image chose to align all the images). The gels were aligned to place all spots in exactly the same location, and afterwards, the spot detection produced a complete data set since all gels contained the same number of spots, each matched to its corresponding spot on all gels. After the alignment, quantification of spot intensity data was performed by the 2D-DIGE module of the SameSpots v4.1 software. All spots from each gel were detected and normalized volume ratios for each protein were calculated using the individual signal of pooled-sample Cy2-labeled as an internal standard. A comparison between PA and PC was performed using the Graph Pad Prism 8.4.2 software.

Protein identification. Spots that exhibited a fold change greater than 1.2 and $p$-value $<0.05$ were taken into consideration for further protein identification. Preparative gels were arranged with $200 \mu \mathrm{g}$ 
of proteins and stained with Ruthenium II tris (bathophenanthroline disulfonate) tetrasodium salt (RuBP) (Cyanagen Srl, Bologna, Italy). Images were acquired with ImageQuant LAS4010 (GE Healthcare Europe) and matched with those of the analytical gels using the SameSpots software. The selected spots were manually cut out from preparative gels, digested with trypsin and identified by nano-liquid chromatography-mass/mass spectrometry (nano-LC-MS/MS) analysis as previously described (14) using a Proxeon EASY-nLCII (Thermo Fisher Scientific, Milan, Italy) chromatographic system coupled to a Maxis HD UHR-TOF (Bruker Daltonics $\mathrm{GmbH}$, Bremen, Germany) mass spectrometer. Briefly, peptides were loaded on the EASY-Column C18 trapping column $(2 \mathrm{~cm} \times 100 \mu \mathrm{m}$ i.d., 5 $\mu \mathrm{m}$ particle size, Thermo Fisher Scientific), and then separated on an Acclaim PepMap100 C18 $(25 \mathrm{~cm} \times 75 \mu \mathrm{m}$ i.d., $5 \mu \mathrm{m}$ particle size, Thermo Fisher Scientific) nanoscale chromatographic column at a flow rate of $300 \mathrm{nl} / \mathrm{min}$ and with a standard gradient from 3 to $35 \%$ of acetonitrile for $15 \mathrm{~min}$. The mass spectrometer was equipped with a nanoESI spray source and operated in positive ion polarity and Auto MS/MS mode (Data Dependent Acquisition DDA), using N2 as collision gas for CID fragmentation. In-source reference lock mass $(1,221.9906 \mathrm{~m} / \mathrm{z})$ was acquired online throughout the runs.

Raw data were processed with DataAnalysis v. 4.2 to apply the lock mass calibration and then loaded in PEAKS Studio v7.5 software (Bioinformatic Solutions Inc, Waterloo, Canada) using the 'correct precursor only' option. The mass lists were searched against the NextProt database (downloaded July 2017 and containing 42,151 entries). Carbamidomethylation of cysteines was selected as fixed modification and oxidation of methionines and deamidation of asparagine and glutamine were set as variable modifications. Non specific cleavage was allowed to one end of the peptides, with a maximum of 2 missed cleavages and 2 variable post translational modifications (PTMs) per peptide. $10 \mathrm{ppm}$ and $0.05 \mathrm{Da}$ were set as the highest error mass tolerances for precursors and fragments, respectively. $-10 \log 10(\mathrm{p})$ threshold for peptide spectrum matches (PSMs) was manually set to 30 .

Bioinformatic analysis. Proteins differentially expressed in PC compared to PA were functionally analyzed using QIAGEN's IPA (QIAGEN Redwood City, USA, www.qiagen.com/ingenuity, Build version: 321501M Content version: 21249400) with the aim to determine the predominant canonical pathways and interaction networks involved. Swiss Prot accession numbers and official gene symbols were inserted into the software along with corresponding comparison ratios and $p$-values. Based on known associations in the literature, canonical pathways associated with differentially expressed proteins were defined. A comparison of the different analyses was created and the upstream regulators whose activity appears to change in a significant manner, according to the activation z-score value, were shown. Finally, the impact of activated or inhibited regulators on downstream functions and diseases were investigated. The use of an algorithm allowed merging upstream and downstream results from the upstream regulator, through one or more iterations. The networks were merged only if the overlap of protein targets was of possible statistical significance (Fisher's exact test). Hypotheses with higher scores were those with more consistent causal paths represented by a high Consistency Score.

Western blot $(W B)$. WB was performed in order to validate the increased expression in PC compared to PA, found by 2D-DIGE, of
UCH-L1, Superoxide Dismutase, Mitochondrial (SOD2) and Annexin A2 (ANXA2).

Aliquots of protein samples (5 PA and 5 PC) $(30 \mu \mathrm{g}$ for $\mathrm{UCH}-$ $\mathrm{L} 1,15 \mu \mathrm{g}$ for SOD2 and ANXA2) were mixed with Laemmli solution, run in $8-16 \%$ polyacrylamide gels (Mini-PROTEAN ${ }^{\circledR}$ Precast Gels, BioRad), using a mini Protean Tetracell (BioRad) and transferred onto nitrocellulose membranes $(0.2 \mu \mathrm{m})$, using a Trans Blot Turbo transfer system (BioRad), as previously described (15). A mouse anti-UCH-L1 antibody (Santa Cruz, sc-271639; Dallas, TX, USA) was used at 1:500 dilution whereas mouse anti-SOD2 (Santa Cruz, sc-133134) and rabbit anti-ANXA2 (Cell Signaling Technology, Beverly, MA, USA) antibodies were used at 1:1,000. In order to normalize the optical density of immune-reactive bands, the total protein optical density was calculated. Therefore, immediately after electrophoresis, the membranes were stained with $1 \mu \mathrm{M}$ RuBP. HRP-goat anti-rabbit and -mouse secondary antibodies were used at the dilution of 1:10,000. Immunoblots were developed using the enhanced chemiluminescence detection system (ECL). The chemiluminescent images were acquired using LAS4010 (GE Health Care Europe). The immunoreactive specific bands were quantified using the Image QuantL software.

Statistical analysis. All quantitative results are expressed as mean \pm standard error of mean (SEM) of 3 replicates for protein spots or 3 to 5 tumor samples for WB analysis. Paired Student's $t$ test was used to assess differences of protein abundance between gels whereas an unpaired Student's $t$-test was performed for WB (Graph Pad Prism 8.4.2 software).

\section{Results}

Proteome changes between PC and PA co-existing in one patient. By 2D-DIGE experiments, three images were produced representing $\mathrm{PC}, \mathrm{PA}$ and the internal standard formed by equal amounts of PC and PA proteins, respectively. Representative 2D-DIGE gel images are shown in Figure 1. Computational comparison of color intensities revealed 43 differentiallyexpressed protein spots out of which 32 were up-regulated and 11 down-regulated in PC, compared to PA. Each deregulated protein spot exhibited greater than 1.2 fold change of mean value intensity (\% of volume) in $\mathrm{PC}$ with respect to PA.

Identification of differentially expressed proteins between PC and PA co-existing in one patient. In order to identify differential expressed proteins showing greater than 1.2 fold change and a $p$-value $<0.05, \mathrm{PC}$ and $\mathrm{PA}$ proteins were separated using preparative 2DE followed by staining with RuBP. Preparative gel images were matched with those of analytical gels (Figures 2, 3, 4) and the spots differentially stained both in 2D-DIGE and 2DE were excised, trypsin digested and analyzed by nanoLC-MS/MS. Figure 5 shows the enlarged images of the most noteworthy protein spots in preparative 2DE gels and histograms of the corresponding volume percentage. All 32 up-regulated protein spots were identified, yielding 23 different proteins. Nine different proteins were found in more than one spot, while more than 

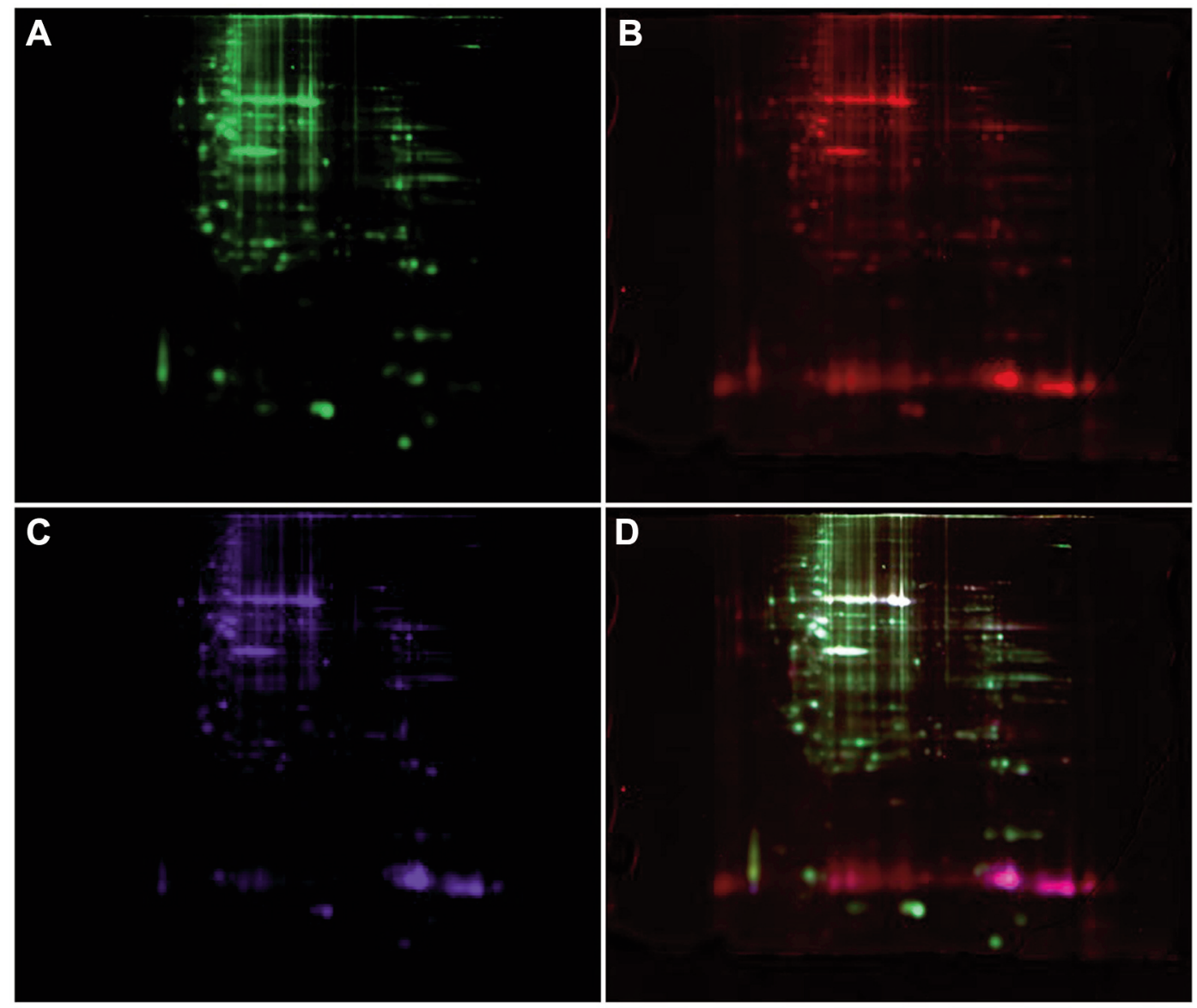

Figure 1. Representative 2D-DIGE images. 2D-DIGE was performed as described in Methods. (A) Cy3-labeled PC proteins; (B) Cy5-labeled PA proteins; (C) Cy2-labeled PA and PC proteins (internal control); (D) superimposed images.

one identifications were reported for one spot, since molecular weight (MW) and isoelectic point (pI) were not distinguishable. All 11 down-regulated protein spots were identified with 2 proteins found in more than one spot. On the other hand, more than one identification was reported for two spots. A list of identified proteins, MW, pI, score and coverage values of MS/MS, expression level fold change, and $p$-values are shown in Table II.

Functional analysis of differentially expressed proteins of $P C$ Ingenuity Pathway Analysis (IPA) software allowed us to find diseases and biological functions in which proteins deregulated in PC are involved. The disease and disorder category included "endocrine system disorders", "inflammatory response" and "gastrointestinal, inflammatory and immunological diseases".

All differentially-expressed proteins in PC were further analyzed to discover potential canonical pathways, upstream regulators and downstream effects derived from their activation or inhibition. The main canonical pathways involved were 14-3-3-mediated signaling, gluconeogenesis, nuclear factor erythroid 2-related factor 2 (NRF2) mediated oxidative stress response, glutathione redox reactions, and TCA cycle. IPA software also generated two main networks, namely "cancer, gastrointestinal, and hepatic system diseases" and "endocrine system disorders, gastrointestinal, and immunological diseases", with 43 and 30 score values, respectively (Figure 6). Moreover, the key molecular and cellular functions involving deregulated proteins were revealed by downstream analysis, which pointed out the following cell functional activities: "cell death and survival", "cellular movement", "molecular transport", "cell cycle", and "free radical scavenging". All differentially-expressed proteins also concurred in an upstream analysis to predict activation or inhibition of potential transcription factors or molecules. Table III shows a list of top activated and inhibited upstream regulators based on both $p$-value and number of targets molecules. 


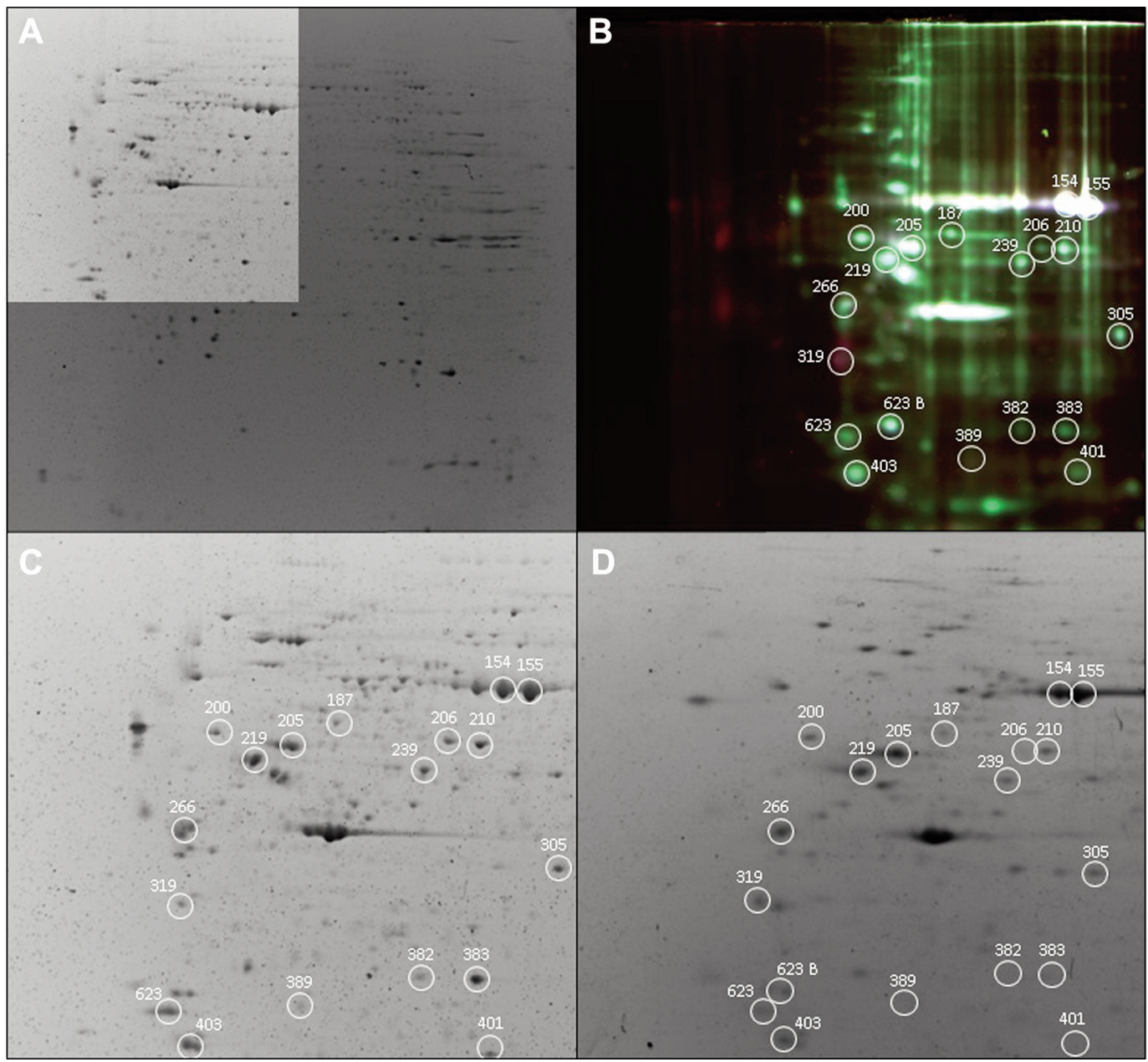

Figure 2. Magnified images of the acid region of $2 D E$ gels showing medium and high molecular weight proteins. (A) A representative image of a whole $2 D E$ gel where the region of interest is highlighted. (B) A representative image of a 2DE-DIGE superimposed gel. The spots found differentially expressed are encircled. $(C)$ A representative image of a preparative RuBP stained $2 D E$-gel of PC proteins and (D) a preparative RuBP stained $2 D E$-gel of PA proteins, where the spots found differentially expressed in $2 D E-D I G E$ analysis are encircled.

Immunoblotting confirmation of changes in selected differentially expressed proteins. Three identified deregulated proteins, UCH-L1, SOD2, and ANXA2, were chosen for validation by WB analysis on PC and PA samples obtained from additional 10 (5 PC and $5 \mathrm{PA}$ ) patients. All three proteins resulted up-regulated in $\mathrm{PC}$ with $\geq 2$-fold change with respect to PA by comparative analysis of 2D-DIGE and preparative 2D gel images. Figure $7 \mathrm{~B}$ shows three representative immunoblots for each parathyroid tumor type. The optical density of each immunoreactive band was measured and normalized over the total density of RuBP stained protein bands. Resulting mean values \pm SEM were compared between PC and PA samples (Figure 7A). WB analysis confirmed the increased expression of all three proteins in PC compared to PA tissues.

\section{Discussion}

PC is a quite rare endocrine tumor with clinical manifestations mainly due to PTH-related hypercalcemia rather than tumor burden. Clinical diagnosis is challenging, although essential for optimal surgical treatment. Histological criteria in the absence of distant metastasis are considered the gold standard for a definitive diagnosis of PC. A few immunohistochemical biomarkers have been also proposed as an adjunct to histology for a correct diagnosis $(2,16)$. Indeed, single biomarkers such as Ki-67, parafibromin, PGP9.5, and galectin-3, are among the most utilized, even though none has yet proven to be clinically useful (4).

To identify the network of key proteins involved in PC pathogenesis and thus open the way to biomarker discovery, 


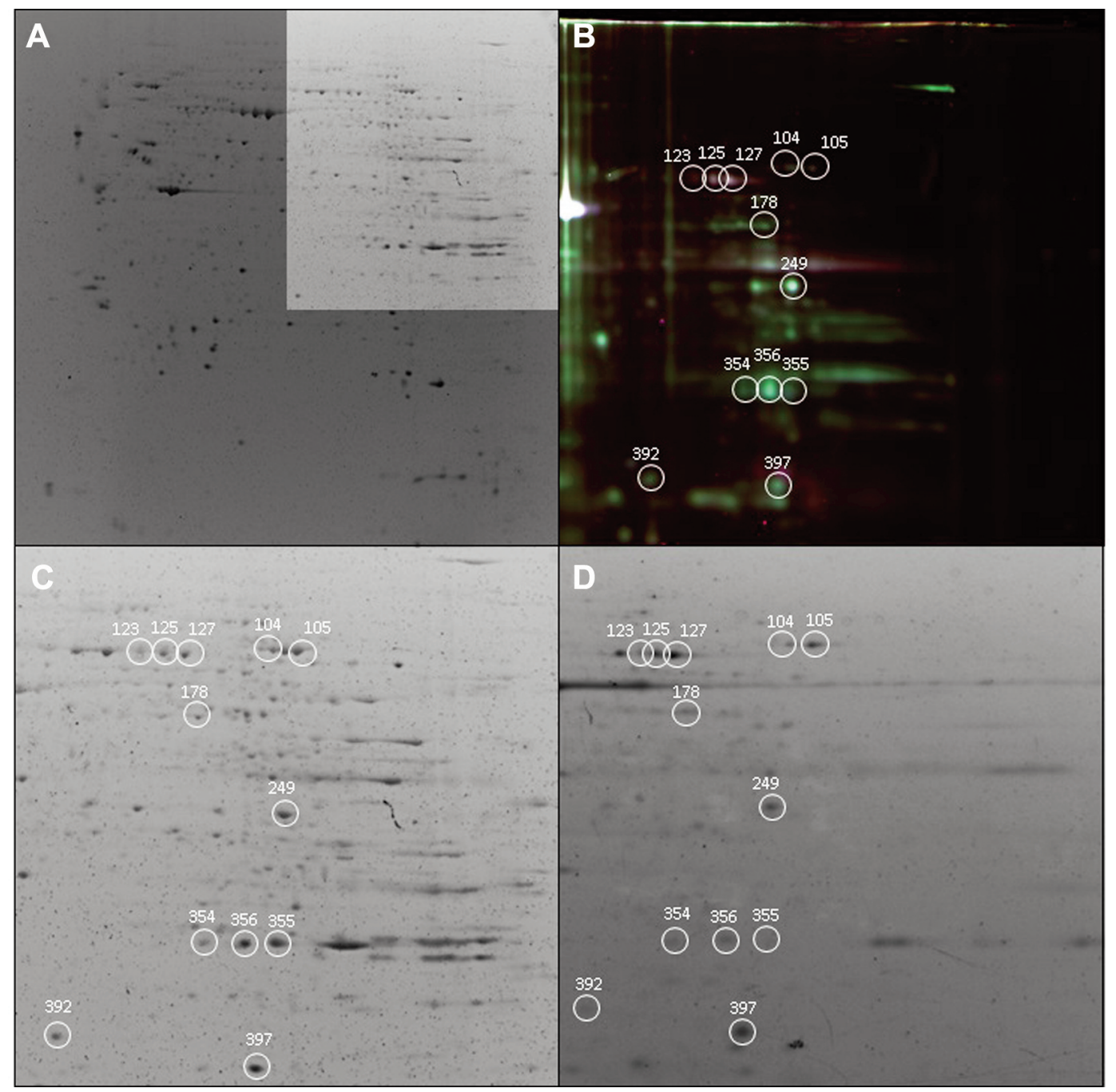

Figure 3. Magnified images of the basic region of 2DE-gels showing medium and high molecular weight proteins. (A) A representative image of a whole $2 D E$ gel, where the region of interest is highlighted. (B) A representative image of a 2DE-DIGE superimposed gel. The spots found differentially expressed are encircled. $(C)$ A representative image of a preparative RuBp stained $2 D E$-gel of $P C$ proteins and (D) a preparative RuBP stained 2DE-gel of PA proteins, where the spots found differentially expressed in 2DE-DIGE analysis are encircled.

we performed a comparative proteomic analysis between PC and PA samples obtained from a single patient suffering from severe PHPT. The co-occurrence of malignant and benign parathyroid lesions is an extremely rare condition and represented a unique opportunity to compare the specific protein signatures without the hindrance due to the biological variability among patients. Using a 2DE coupled to LCMS/MS approach, a total of 33 differentially-expressed proteins were identified, of them 23 resulted over-expressed and 10 under-expressed in PC compared to PA. WB analysis used as validation study of three over-expressed proteins in PC, UCH-L1, ANXA2 and SOD2, confirmed proteomic results on additional parathyroid tumor samples. Identified proteins participate in a variety of biological functions including protein ubiquitination [UCH-L1, $60 \mathrm{kDa}$ heat shock protein, mitochondrial (HSPD1), proteasome subunit alpha type-6 (PSMA6)], cellular metabolism [cytoplasmic malate dehydrogenase (MDH1), aconitate hydratase, mitochondrial (ACO2), $\alpha$-enolase (ENO1), phosphoglycerate mutase 1 (PGAM1)], cell signaling [14-3-3 protein $\zeta / \delta$ (YWHAZ), 14-3-3 protein $\varepsilon$ (YWHAE), protein disulfide isomerase A3 (PDIA3), tubulin $\beta-4 B$ chain (TUBB4B), vimentin (VIM)) and oxidative stress response (SOD2, glutathione S-transferase P (GSTP1), glutathione Stransferase $\omega 1$ (GSTO1), endoplasmic reticulum resident protein 29 (ERP29), actin cytoplasmic 2 (ACTG1)]. 


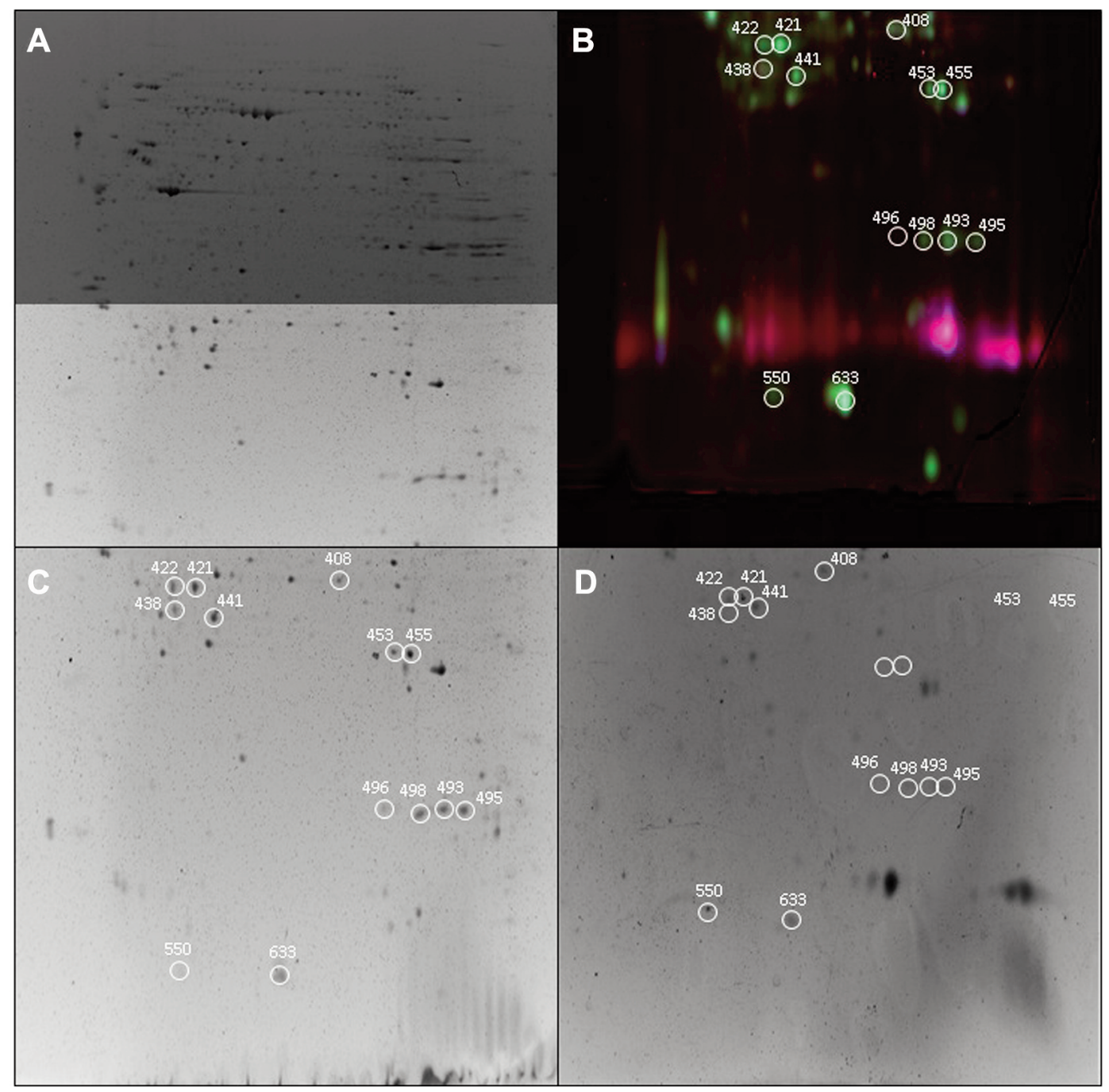

Figure 4. Magnified images of acidic and basic regions of 2DE-gels showing low molecular weight proteins. (A) A representative image of a whole $2 D E$ gel, where the region of interest is highlighted. (B) A representative image of a $2 D E-D I G E$ superimposed gel. The spots found differentially expressed are encircled. $(C)$ A representative image of a preparative $R U B P$ stained $2 D E$ gel of $P C$ proteins and $(D)$ a preparative RuBP stained $2 D E$-gel of PA proteins, where the spots found differentially expressed in $2 D E-D I G E$ analysis are encircled.

Our data indicated that UCH-L1, also known as PGP9.5, was highly over-expressed in PC. This enzyme, a member of deubiquitinase (DUB) family, is a thiol protease involved in processing ubiquitin precursors and probably also ubiquitinated proteins. UCH-L1, which is highly expressed in neuronal and endocrine cells, has both hydrolase and ligase activities (17). All DUBs play important roles in pathways usually dysregulated in cancer, such as DNA repair, cell growth, and apoptosis. It has been also reported that UCH-L1 acts either as an oncogene or a tumor suppressor gene depending on the types of cancers (18-21).

Recently, an epigenetic mechanism has been suggested in the regulation of UCH-L1 promoter on the basis of the observation that UCH-L1 is significantly down-regulated in nasopharyngeal carcinoma (NPC) exhibiting promoter hypermethylation whereas the restoration of UCH-L1 suppressed NPC invasion and metastasis via ubiquitin ligase degradation of cortactin (22). On the other hand, the DUB activity of UCH-L1 appears to promote tumorigenesis in hypoxic conditions via activation of the TGF /SMAD signaling (23). Taking into account UCH-L1 involvement in cancer, it is not surprising that IPA included the enzyme in the "cancer, gastrointestinal, and hepatic system diseases" network, together with other over- and under-expressed proteins.

Haven et al. (24) firstly found the up-regulation of UCHL1 mRNA in a cluster of tumors containing CDC73 mutated 


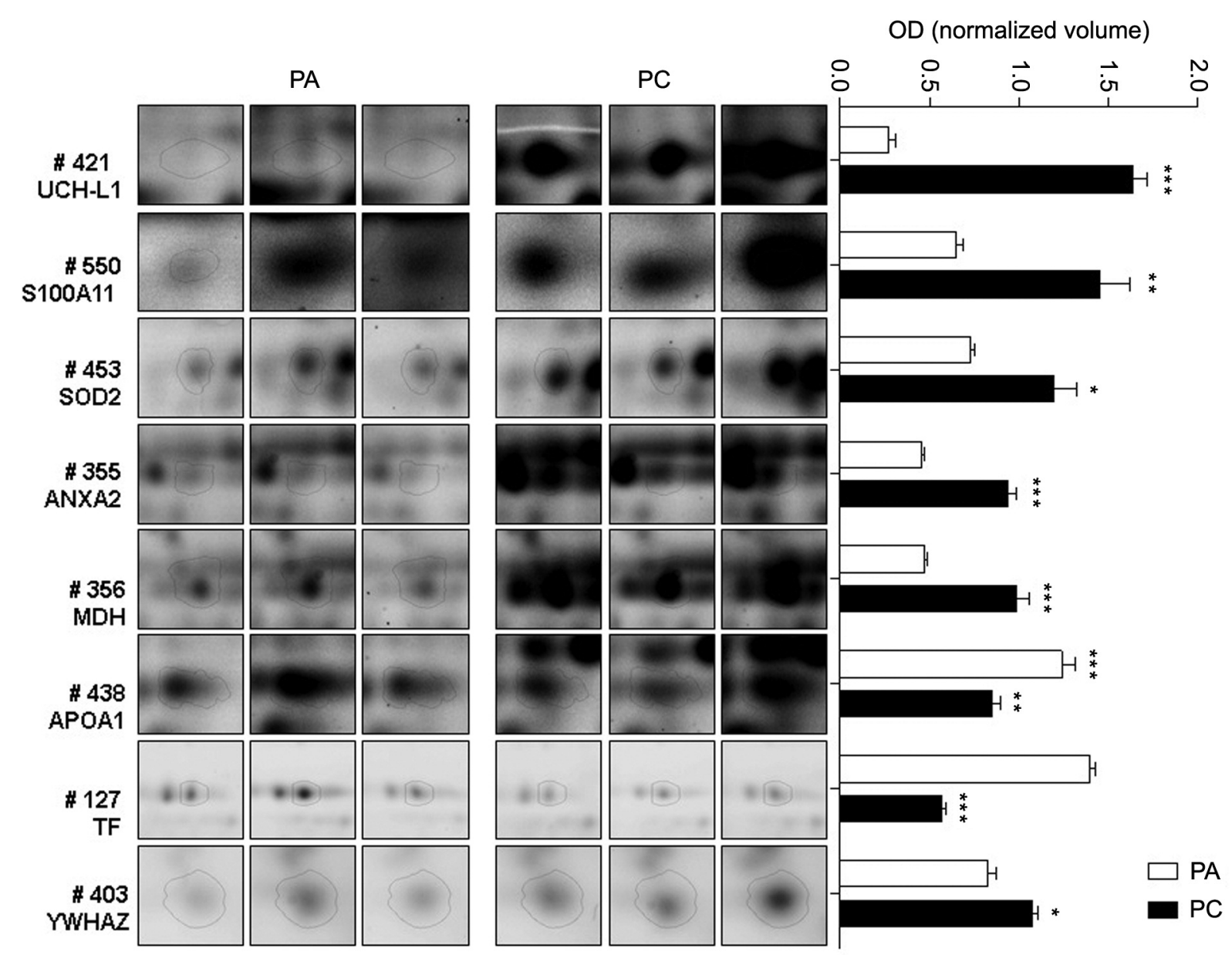

Figure 5. Enlarged images of selected $2 \mathrm{D}$ gel spots to highlight differential expression. (A) Preparative $2 D$ gels were stained using RuBP, images acquired, matched with 2D-DIGE and compared. Protein spots identified as ubiquitin carboxyl-terminal hydrolase isozyme L1 (UCH-L1), proteinS100-A11 (S100A11), cytoplasmic malate dehydrogenase (MDH) 1, annexin A2 (ANXA2), superoxide dismutase, mitochondrial (SOD2), 14-3-3 protein $\xi / \delta(Y W H A Z)$, apolipoprotein-A1 (APOA1), and serotransferrin $(T F)$ are from representative gels. Spot number and corresponding identified protein are listed in Table II. (B) Histograms of each spot volume (\%) showing the fold-change in PC compared to PA. Data are presented as mean $\pm S E M$ of the normalized spot volumes of three gel replicates. Normalization was performed as described in Methods. Statistical analysis was performed using paired Student's t-test: $* p<0.05, * * p<0.01$, ***p<0.001.

sporadic and familial PCs and CDC73 mutated familial benign adenomas. UCH-L1 up-regulation has been also confirmed in one case of PC compared to normal parathyroid gland of the same patient (25). Of interest, a strong immunostaining for PGP9.5 has been reported in PCs and PGP9.5, either as single marker or combined in a panel together with $\mathrm{Ki}-67$, parafibromin, adenomatous polyposis coli protein (APC) and galectin-3, may be used as a helpful diagnostic adjunct for the diagnosis of challenging parathyroid lesions (26-30).

Among the over-expressed proteins in the "cancer, gastrointestinal, and hepatic system diseases" network, ANXA2 is a $36 \mathrm{kDa}$ multifunctional protein, which binds to membrane phospholipids in a $\mathrm{Ca}^{2+}$-regulated manner mediating many aspects of intercellular and extracellular microenvironment communications and cell survival. Increased expression of ANXA2 has been found in a variety of cancers correlating to invasiveness and metastasis (31). We and other authors have reported an increased expression of ANXA2 in PA compared to normal and hyperplastic parathyroid tissues, respectively $(10,13)$. Interestingly, $\mathrm{Hu}$ et al. (32) have found an increased expression of hsa_circRNA_0035563 and its corresponding linear transcript, ANXA2, in PC compared to PA and a correlation with recurrence in $\mathrm{PC}$ patients.

Another protein found over-expressed in PC compared to $\mathrm{PA}$ is $\mathrm{S} 100-\mathrm{A} 11$, a member of the $\mathrm{S} 100$ protein family, which includes small EF-hand-type $\mathrm{Ca} 2+$ binding proteins exerting 
Table II. List of proteins identified by nano-liquid chromatography-mass/mass spectrometry (LC-MS/MS).

\begin{tabular}{|c|c|c|c|c|c|c|c|c|c|c|c|c|}
\hline Spot $n^{\circ}$ & $\begin{array}{l}\text { Protein } \\
\text { name }\end{array}$ & ID & Gene & Peptides & $\begin{array}{l}\text { Unique } \\
\text { peptides }\end{array}$ & $\begin{array}{l}\text { Coverage } \\
(\%)\end{array}$ & MW & $\mathrm{pI}$ & $\begin{array}{c}\text { MW } \\
\text { obs }\end{array}$ & $\begin{array}{c}\mathrm{pI} \\
\mathrm{obs}\end{array}$ & $\begin{array}{l}\text { Ratio } \\
\mathrm{PC} / \mathrm{PA}\end{array}$ & $p$-Value \\
\hline \multicolumn{13}{|c|}{ Underexpressed in parathyroid carcinoma } \\
\hline 397 & Phosphoglycerate mutase 1 & P18669 & PGAM1 & 22 & 12 & 69 & 29 & 6.7 & 26 & 7.4 & 0.20 & 0.00168 \\
\hline 319 & Actin, cytoplasmic 2 & P63261 & ACTG1 & 9 & 9 & 28 & 42 & 5.3 & 41 & 4.6 & 0.38 & 0.00006 \\
\hline 123 & Serotransferrin & P02787 & $T F$ & 34 & 34 & 51 & 77 & 6.8 & 77 & 6.8 & 0.46 & 0.00003 \\
\hline 127 & Serotransferrin & P02787 & $T F$ & 47 & 47 & 58 & 77 & 6.8 & 77 & 7.1 & 0.40 & 0.00008 \\
\hline 125 & Serotransferrin & $\mathrm{P} 02787$ & $T F$ & 46 & 46 & 55 & 77 & 6.8 & 77 & 6.9 & 0.43 & 0.00007 \\
\hline 154 & Serum albumin & P02768 & $A L B$ & 61 & 61 & 74 & 69 & 5.9 & 69 & 5.9 & 0.44 & 0.00014 \\
\hline 155 & Serum albumin & P02768 & $A L B$ & 56 & 56 & 63 & 69 & 5.9 & 69 & 6.3 & 0.44 & 0.00018 \\
\hline 205 & Vimentin & P08670 & VIM & 42 & 39 & 70 & 54 & 5.0 & 61 & 5.0 & 0.60 & 0.00145 \\
\hline 205 & Vitamin D-binding protein & $\mathrm{P} 02774$ & $G C$ & 4 & 4 & 7 & 55 & 5.5 & 61 & 5.0 & 0.60 & 0.00145 \\
\hline 438 & Apolipoprotein A-I & P02647 & APOA1 & 9 & 9 & 35 & 31 & 5.5 & 24 & 5.2 & 0.68 & 0.00747 \\
\hline 266 & Reticulocalbin-1 & Q15293 & $R C N 1$ & 27 & 27 & 56 & 39 & 4.8 & 49 & 4.7 & 0.84 & 0.02134 \\
\hline 408 & Peroxiredoxin-6 & P30041 & PRDX6 & 22 & 21 & 69 & 25 & 6.0 & 25 & 6.8 & 0.85 & 0.01947 \\
\hline 408 & Proteasome subunit $\alpha$ type- 6 & P60900 & PSMA6 & 10 & 10 & 42 & 27 & 6.3 & 25 & 6.8 & 0.85 & 0.01947 \\
\hline \multicolumn{13}{|c|}{ Overexpressed in parathyroid carcinoma } \\
\hline 249 & $\alpha$-enolase & P06733 & ENO1 & 32 & 32 & 58 & 47 & 7.0 & 52 & 7.6 & 1.20 & 0.03690 \\
\hline 104 & $\begin{array}{l}\text { Aconitate hydratase, } \\
\text { mitochondrial }\end{array}$ & Q99798 & ACO2 & 35 & 35 & 52 & 85 & 7.4 & 80 & 7.5 & 1.26 & 0.01562 \\
\hline 219 & Tubulin $\beta-4 \mathrm{~B}$ chain & P68371 & $T U B B 4 B$ & 44 & 5 & 77 & 50 & 4.8 & 58 & 4.9 & 1.27 & 0.01579 \\
\hline 623 & 14-3-3 protein $\varepsilon$ & P62258 & $Y W H A E$ & 27 & 27 & 76 & 29 & 4.6 & 30 & 4.6 & 1.31 & 0.03566 \\
\hline 623 & Tropomyosin $\alpha-4$ chain & P67936 & TPM4 & 29 & 17 & 64 & 29 & 4.7 & 33 & 4.6 & 1.31 & 0.03566 \\
\hline 403 & $14-3-3$ protein $\zeta / \delta$ & P63104 & $Y W H A Z$ & 21 & 14 & 69 & 28 & 4.7 & 26 & 4.7 & 1.31 & 0.01752 \\
\hline 105 & Aconitate hydratase, mitochondrial & Q99798 & ACO2 & 39 & 39 & 48 & 85 & 7.4 & 80 & 7.7 & 1.34 & 0.02348 \\
\hline 239 & $\begin{array}{l}\text { Spliceosome RNA } \\
\text { helicase DDX39B }\end{array}$ & Q13838 & $D D X 39 B$ & 10 & 10 & 21 & 51 & 5.6 & 57 & 5.6 & 1.34 & 0.01349 \\
\hline 200 & Protein disulfide-isomerase & P07237 & $P 4 H B$ & 36 & 36 & 63 & 57 & 4.7 & 62 & 4.8 & 1.37 & 0.02617 \\
\hline 210 & Protein disulfide-isomerase A3 & P30101 & PDIA3 & 47 & 47 & 65 & 57 & 5.9 & 60 & 5.8 & 1.38 & 0.00425 \\
\hline 187 & $\begin{array}{l}60 \mathrm{kDa} \text { heat shock protein, } \\
\text { mitochondrial }\end{array}$ & P10809 & HSPDI & 46 & 46 & 61 & 61 & 5.7 & 64 & 5.2 & 1.41 & 0.03579 \\
\hline 206 & Protein disulfide-isomerase A3 & P30101 & PDIA3 & 36 & 36 & 57 & 57 & 5.9 & 61 & 5.7 & 1.42 & 0.01559 \\
\hline 495 & $\begin{array}{l}\text { Peptidyl-prolyl cis-trans } \\
\text { isomerase A }\end{array}$ & P62937 & PPIA & 20 & 19 & 75 & 18 & 7.7 & 18 & 8.1 & 1.42 & 0.00416 \\
\hline 305 & Macrophage-capping protein & P40121 & $C A P G$ & 25 & 25 & 43 & 38 & 5.8 & 44 & 6.5 & 1.44 & 0.00011 \\
\hline 498 & $\begin{array}{l}\text { Peptidyl-prolyl cis-trans } \\
\text { isomerase A }\end{array}$ & P62937 & PPIA & 13 & 13 & 67 & 18 & 7.7 & 18 & 7.7 & 1.45 & 0.00093 \\
\hline 401 & $\begin{array}{l}\text { Endoplasmic reticulum } \\
\text { resident protein } 29\end{array}$ & P30040 & ERP29 & 15 & 15 & 52 & 29 & 6.7 & 26 & 5.9 & 1.51 & 0.04005 \\
\hline 178 & Prelamin-A/C & P02545 & LMNA & 47 & 46 & 68 & 65 & 6.4 & 65 & 7.1 & 1.53 & 0.00047 \\
\hline 441 & Glutathione S-transferase P & P09211 & GSTP1 & 33 & 33 & 69 & 23 & 5.4 & 24 & 5.5 & 1.60 & 0.00907 \\
\hline 453 & $\begin{array}{l}\text { Superoxide dismutase }[\mathrm{Mn}] \text {, } \\
\text { mitochondrial }\end{array}$ & P04179 & $S O D 2$ & 10 & 10 & 36 & 19,7 & 7.8 & 23 & 7.4 & 1.64 & 0.01299 \\
\hline 496 & $\begin{array}{l}\text { Peptidyl-prolyl cis-trans } \\
\text { isomerase A }\end{array}$ & P62937 & PPIA & 9 & 9 & 47 & 18 & 7.6 & 18 & 7.3 & 1.66 & 0.04039 \\
\hline 493 & $\begin{array}{l}\text { Peptidyl-prolyl cis-trans } \\
\text { isomerase A }\end{array}$ & P62937 & PPIA & 17 & 17 & 60 & 18 & 7.6 & 18 & 7.9 & 1.66 & 0.03170 \\
\hline 392 & Glutathione S-transferase $\omega-1$ & P78417 & GSTO1 & 27 & 27 & 64 & 28 & 6.2 & 27 & 6.3 & 1.73 & 0.02476 \\
\hline 633 & Protein S100-A11 & P31949 & S100A11 & 13 & 13 & 71 & 12 & 6.5 & 12 & 6.6 & 1.77 & 0.02421 \\
\hline 354 & Annexin A2 & P07355 & $A N X A 2$ & 17 & 17 & 47 & 39 & 7.5 & 38 & 7.1 & 2.00 & 0.00127 \\
\hline 354 & $\begin{array}{l}\text { Malate dehydrogenase, } \\
\text { cytoplasmic }\end{array}$ & P40925 & $M D H 1$ & 6 & 6 & 18 & 36 & 6.9 & 38 & 7.1 & 2.00 & 0.00127 \\
\hline 455 & $\begin{array}{l}\text { Superoxide dismutase }[\mathrm{Mn}] \text {, } \\
\text { mitochondrial }\end{array}$ & P04179 & $S O D 2$ & 27 & 26 & 59 & 25 & 8.3 & 23 & 7.6 & 2.00 & 0.00097 \\
\hline 355 & Annexin A2 & P07355 & ANXA2 & 53 & 53 & 76 & 39 & 7.6 & 38 & 7.5 & 2.10 & 0.00047 \\
\hline
\end{tabular}


Table II. Continued

\begin{tabular}{|c|c|c|c|c|c|c|c|c|c|c|c|c|}
\hline Spot $n^{\circ}$ & $\begin{array}{l}\text { Protein } \\
\text { name }\end{array}$ & ID & Gene & Peptides & $\begin{array}{l}\text { Unique } \\
\text { peptides }\end{array}$ & $\begin{array}{l}\text { Coverage } \\
(\%)\end{array}$ & MW & $\mathrm{pI}$ & $\begin{array}{c}\text { MW } \\
\text { obs }\end{array}$ & $\begin{array}{c}\mathrm{pI} \\
\mathrm{obs}\end{array}$ & $\begin{array}{l}\text { Ratio } \\
\mathrm{PC} / \mathrm{PA}\end{array}$ & $p$-Value \\
\hline 356 & $\begin{array}{l}\text { Malate dehydrogenase, } \\
\text { cytoplasmic }\end{array}$ & P40925 & $M D H 1$ & 13 & 13 & 34 & 39 & 7.6 & 38 & 7.4 & 2.10 & 0.00067 \\
\hline 389 & $\begin{array}{l}\text { Chloride intracellular } \\
\text { channel protein } 1\end{array}$ & O00299 & CLIC1 & 24 & 24 & 69 & 27 & 5.1 & 29 & 5.1 & 2.20 & 0.01001 \\
\hline 550 & Protein S100-A11 & P31949 & S100A11 & 4 & 4 & 27 & 12 & 6.5 & 12 & 5.2 & 2.25 & 0.00360 \\
\hline 382 & Annexin A4 & P09525 & ANXA4 & 22 & 22 & 54 & 36 & 5.8 & 32 & 5.5 & 2.50 & 0.00001 \\
\hline 383 & Annexin A4 & P09525 & ANXA4 & 74 & 71 & 78 & 36 & 5.8 & 36 & 5.8 & 3.00 & 0.00282 \\
\hline 422 & $\begin{array}{l}\text { Ubiquitin carboxyl-terminal } \\
\text { hydrolase isozyme L1 }\end{array}$ & P09936 & UCHL1 & 20 & 20 & 77 & 25 & 5.3 & 25 & 5.2 & 3.60 & 0.00069 \\
\hline 421 & $\begin{array}{l}\text { Ubiquitin carboxyl-terminal } \\
\text { hydrolase isozyme L1 }\end{array}$ & P09936 & UCHL1 & 55 & 54 & 87 & 25 & 5.3 & 25 & 5.3 & 5.96 & 0.00017 \\
\hline
\end{tabular}

Protein ID: SwissProt accession number; PI and MW: theoretical and observed isoelectric point and molecular weight (kDa), PC: parathyroid carcinoma; PA: parathyroid adenoma.

both intracellular and extracellular functions upon $\mathrm{Ca}^{2+}$ activation. Over-expression of S100-A11 has been reported in several tumors where it associates with metastasis and poor prognosis (33). S100 proteins can interact and form complexes with annexins, such as the S100-A10 and ANXA2 heterotrimeric complex. A role of S100-A11 and the binding partner ANXA2 in plasma membrane repair of cancer cells has been described (34). However, we have previously found an increased expression of S100-A11 in PA compared to normal parathyroid tissue (10).

14-3-3 $\zeta$ protein, encoded by the YWHAZ gene, is a key protein in common and specialized signaling pathways and is the central hub within the protein network shown in Figure 3A. The family of 14-3-3 proteins includes phospho-binding proteins which regulate every main cellular function including cell cycle progression, glucose metabolism, autophagy and cell motility (35). 14-3-3 proteins control and regulate multiple signaling pathways through dynamic interactions with a multitude of proteins, which respond to environmental condition changes. Therefore, these proteins are now considered pivotal players in cancer, allowing cancer cell to adapt to adverse growth conditions. Many lines of evidence indicate that $14-3-3 \zeta$ plays a central role in promoting oncogenic and chemoresistance pathways in cancer (31). Our data showed that 14-3-3 $\zeta$ protein was overexpressed in $\mathrm{PC}$ with respect to $\mathrm{PA}$ albeit at a $\mathrm{PC} / \mathrm{PA}$ ratio of only 1.31. Of note, the protein has also been found upregulated in PA with respect to normal parathyroid tissue (10). Interestingly, in PC, at variance with PA, the upregulation of 14-3-3 $\zeta$ was associated with the increased expression of 14-3-3 $\varepsilon$, encoded by the YWAHE gene. An increased expression of 14-3-3 $\zeta$ has been also observed in malignant thyroid nodules with respect to benign nodules (36). 14-3-3 $\xi$ and 14-3-3 \& can form both active homodimers and heterodimers, which directly interact with and regulate target phospho-proteins including some overand under-expressed in PC. 14-3-3 $\zeta$ forms straight interactions with the up-regulated ANXA2, mitochondrial 60 $\mathrm{kDa}$ heat shock protein (HSP60), prelamin-A/C (LMNA) proteins, and ENO1, a glycolytic/gluconeogenetic enzyme, as well as with the down-regulated VIM, ACTG1, and PGAM1, another glycolytic enzyme, shown in the protein network of Figure $3 \mathrm{~A}$. In this network, both direct and indirect interactions of 14-3-3 $\zeta$ with important elements of various signaling cascades are also presented. Although 143-3 $\zeta$ and other proteins (ANXA2, S100-A11 and HSP60) were found over-expressed both in PC and PA, the protein networks obtained by IPA of deregulated proteins were quite different, suggesting that the whole protein set makes the difference between PC and PA.

Mitochondrial HSP60 coded by HSPD1 gene is another protein whose expression was increased in $\mathrm{PC}$ with respect to PA; however, it has also been shown to be over-expressed in PA with respect to normal parathyroid tissue, as reported by Giusti et al. (10). HSP60 is a chaperonin, which facilitates the correct folding of imported proteins and macromolecule assembly inside mitochondrial matrix. All HSPs operate in a variety of physiological and protective processes to prevent cellular homeostasis perturbation. In particular, HSP60 plays an important role in regulating mitochondrial functions as indicated by HSP60-dependent folding of the SOD2 protein, a key antioxidant enzyme, to the native state (37) and is implicated in tumor cell proliferation, metastasis and drug resistance (38). HSP60 may function as promoter or suppressor of carcinogenesis depending on the tumor type. In ovarian cancer, HSP60 increased expression drives tumor progression while it limits the metastatic potential of hepatocellular carcinoma $(39,40)$. 

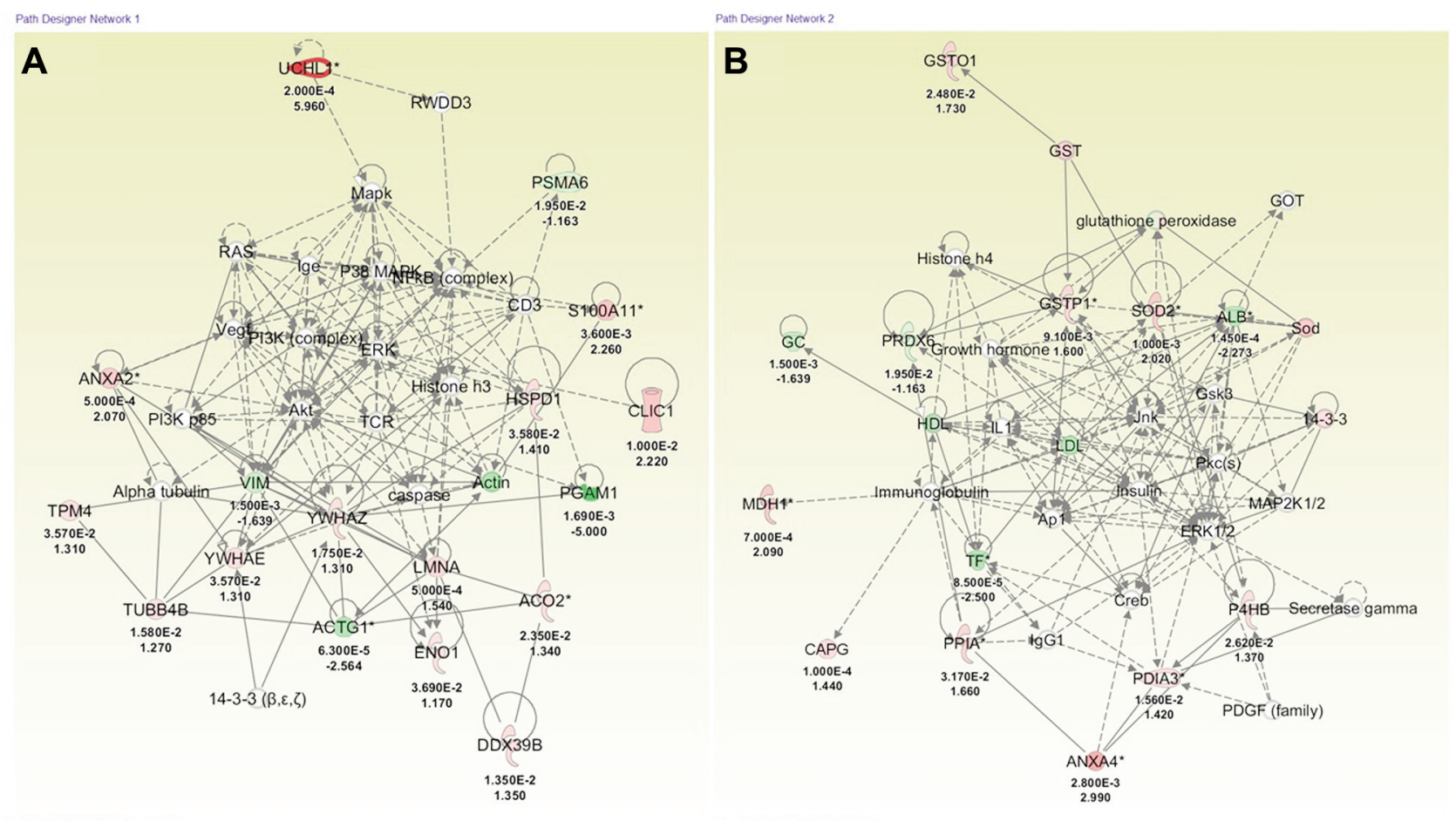

Figure 6. Network analysis of differentially expressed proteins using Ingenuity Pathways Analysis (IPA) software. Proteins showing significant changes in PC compared to PA were analyzed by IPA. (A) The most significant connections of the global network with 43 score value, consisting of 16 deregulated proteins in PC (red, up-regulated proteins; green, down-regulated proteins) and additional interacting molecules, are indicated. Both direct (solid lines) and indirect (dashed lines) protein-protein interactions or regulations are shown and are based on data published in the literature. (B) The most significant connections of the global network with 30 score value, consisting of 13 deregulated proteins in PC (red, upregulated proteins; green, down-regulated proteins) and additional interacting molecules, are indicated. Both direct (solid lines) and indirect (dashed lines) protein-protein interactions or regulations are shown and are based on data published in the literature.

To our knowledge, the only endocrine carcinoma showing HSP60 up-regulation is the papillary thyroid carcinoma harboring a specific serine/threonine-protein kinase B-raf (BRAF) mutation (T1799A) (41, 42). Notably, HSP60 overexpression negatively correlates to the presence of lymph node metastasis (41). Conversely, our patient had metastatic lymph nodes, which may suggest a different role of HSP60 in papillary thyroid carcinoma and PC progression.

In this study we also found the over-expression of the protein encoded by chloride intracellular channel protein 1 (CLIC1) gene in PC. CLIC1 is usually expressed in the cytoplasm, nucleus, endoplasmic reticulum and plasmatic membranes, where forms membrane bound chloride channels. CLIC1 membrane insertion is redox regulated and seems to occur only in oxidizing conditions. This chloride ion channel is involved in regulating cell cycle, cell proliferation and differentiation. Increased expression of CLIC1 has been reported in different cancer types including breast ductal carcinoma, ovarian cancer, and high grade gliomas (43-46).
It has also been proposed as an ovarian cancer biomarker since it was detectable in soluble form in the plasma of patients (44). Interestingly, CLIC1 is considered both a sensor of reactive oxygen species (ROS), which promote its translocation to the membrane and a necessary effector as the chloride current supports ROS production by NADPH oxidase (46). ROS, which are considered as second messengers regulating cellular metabolism and growth, can exhibit both positive and negative activities depending on their amount. Cancer cells frequently have a higher production of ROS due to their increased growth demands and hypoxic tumor microenvironment.

Taking into account all deregulated proteins in PC, IPA software included within activated canonical pathways the NRF2-mediated oxidative stress response. NRF2 is a transcription factor which regulates the cellular defense against oxidative and stress insults through the expression of genes involved in oxidative stress response and drug detoxification. NRF2 activation induces the expression of 
Table III. List of top upstream regulators obtained by means of Ingenuity Pathways Analysis (IPA) analysis of parathyroid carcinoma (PC) differentially expressed proteins.

\begin{tabular}{|c|c|c|c|c|}
\hline Upstream regulator & Molecule type & $\begin{array}{l}\text { Activation } \\
\text { z-score }\end{array}$ & $p$-Value & Target molecules \\
\hline MYCN & Transcription regulator & 2 & 7.62E-04 & ACTG1, HSPD1, UCH-L1, VIM \\
\hline NFE2L2 & Transcription regulator & 1.594 & 7.75E-09 & $\begin{array}{l}\text { ACTG1, DDX39B, ERP29, GSTO1, GSTP1, } \\
\text { LMNA, PDIA3, PSMA6, SOD2 }\end{array}$ \\
\hline FOS & Transcription regulator & 1.528 & $1.36 \mathrm{E}-04$ & ACTG1, ANXA4, ENO1, GSTP1, VIM, YWHAZ \\
\hline TP53 & Transcription regulator & 1.319 & $4.86 \mathrm{E}-05$ & $\begin{array}{c}\text { ACO2, ALB, ANXA2, ANXA4, GC, GSTP1, HSPD1, } \\
\text { P4HB, PRDX6, SOD2, VIM }\end{array}$ \\
\hline ANGPT2 & Growth factor & 1.206 & 9.64E-06 & HSPD1, P4HB, PDIA3, SOD2, VIM \\
\hline PDGF* & Group & 1 & $4.87 \mathrm{E}-10$ & HSPD1, P4HB, PDIA3, VIM \\
\hline MYC & Transcription regulator & 0.873 & $3.28 \mathrm{E}-06$ & $\begin{array}{c}\text { ALB, ANXA4, DDX39B, ENO1, HSPD1, } \\
\text { PGAM1, PPIA, SOD2, TF, VIM }\end{array}$ \\
\hline $\mathrm{E} 2 \mathrm{~F} 1$ & Transcription regulator & 0 & $6.38 \mathrm{E}-06$ & CLIC1, DDX39B, HSPD1, MDH1, SOD2, VIM, YWHAE \\
\hline
\end{tabular}

*(Family)

over 250 genes, which regulate diverse processes beside redox homeostasis, such as carbohydrate and lipid metabolism, autophagy, apoptosis and DNA repair (47). SOD2 represents one of the essential player of the antioxidant system of the cell, in which in the mitochondrial matrix promotes the dismutation of the superoxide anion to hydrogen peroxide, preventing mitochondrion damage. Due to this scavenging function, SOD2 has been considered a tumor suppressor for a long time, but later became clear that several cancers increase its expression depending on the stage of tumor progression (48). SOD2 expression is dynamically regulated at transcriptional level by multiple activators and repressors, although ROS-dependent activation of NRF2 appears to promote SOD2 overexpression in advanced cancer (47). In our PC sample, SOD2 was clearly up-regulated compared to the matched PA sample and validation analysis confirmed the significant over-expression in five unrelated PC compared to PA samples. At surgery, our patient clearly presented an advanced PC infiltrating the thyroid tissue and the lymph nodes of the central compartment, suggesting a correlation with SOD2 increased expression as reported for other cancers (48). Interestingly, SOD2 up-regulation seemed to correlate with the concomitant increased expression of HSP60 in the PC of the patient compared to the PA. We would underline that SOD2 over-expression has been also reported in anaplastic thyroid cancer compared to poorly differentiated thyroid cancer, while other thyroid cancer types showed either normal or reduced expression (49). In addition, reduced SOD2 expression in anaplastic thyroid cancer and adrenocortical carcinoma correlates with poorer survival of patients (49).

Three metabolic enzymes, namely $\mathrm{MDH} 1, \mathrm{ACO} 2$, and ENO1, were up-regulated in PC compared to PA while

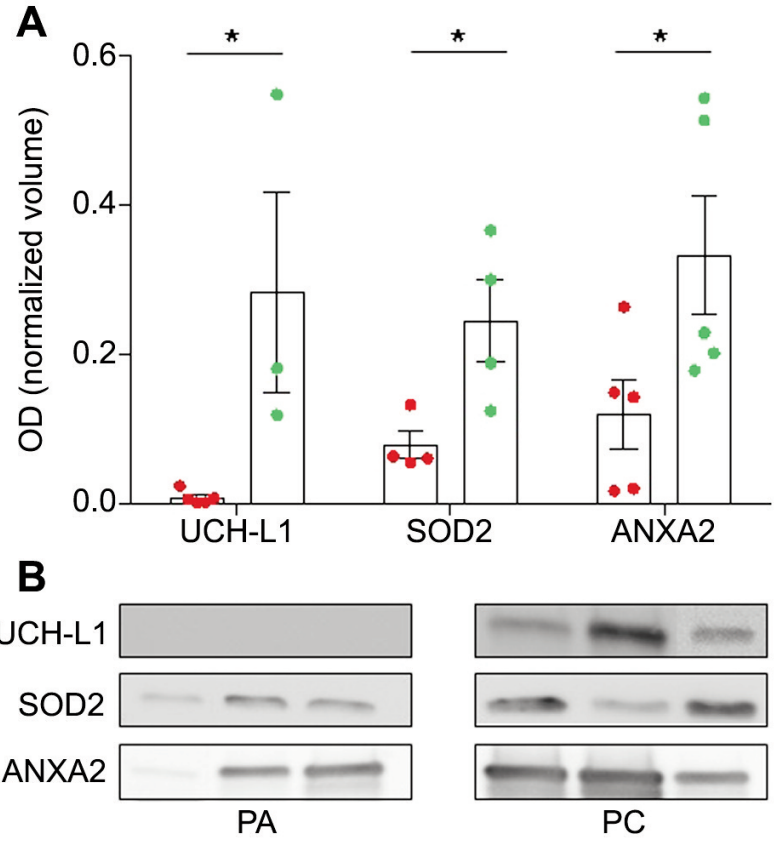

Figure 7. Validation of UCH-L1, SOD2 and ANXA2 differential expression by western blot analysis. (A) Bar graph showing band normalized optical density values. The total density of RuPB stained bands in each lane was used for internal normalization of immunostained bands. Data represent mean value \pm SEM of three to five parathyroid tumor specimens analyzed. Significantly different values ( $P C$ vs. PA), as determined by the unpaired Student t-test, are indicated $(* p<0.05)$. (B) A representative experiment showing the immunoreactive bands of three different tissue samples for each tumor type. Protein electrophoretic separation, transfer to nitrocellulose membrane and immunostaining were performed as described in Materials and Methods. Five PC (green symbol) and 5 PA (red symbol) samples were analyzed for each specific protein except when the surgical specimen was available in a limited amount. PC: Parathyroid carcinoma; PA: parathyroid adenoma. 
PGAM1, which catalyzes a critical step of glycolysis, was down-regulated. Among the up-regulated enzymes, MDH1 showed the most prominent variation. This cytosolic enzyme, as well as the mitochondrial isoenzyme, MDH2, catalyzes the NAD/NADH-dependent reversible oxidation of malate to oxaloacetate, playing a key role in the malate aspartate shuttle across the mitochondrial membrane. The mRNA of both isoenzymes MDH1 and MDH2 has been found significantly elevated in non small cell lung carcinoma (NSCLC) (50). However, only MDH1 expression seems to be associated with poor prognosis (50). Wang et al. (51) have demonstrated that MDH1 is overexpressed in pancreatic ductal adenocarcinoma, where it is involved in an unconventional metabolic pathway required to sustain glutamine metabolism. Further studies have confirmed the pivotal role of MDH1 for the metabolic requirements of cancer cells cooperating with lactate dehydrogenase (LDH) to NAD regeneration needed for glycolysis (52). Therefore, the increased expression of MDH1 in PC points out the metabolic reprogramming of the tumor as also supported by the increased and reduced expression of ENO1 and ACO2, and PGM1, respectively. PGM1 decreased expression suggests that PC cells may prefer to divert glucose carbon atoms towards biosynthetic pathways. Furthermore, MDH1 can be proposed as a malignancy marker of parathyroid tumors since it is not upregulated in PA $(10,13)$.

The main limitation of our study is the rarity of parathyroid carcinoma is a cancer. The presence of PC and $\mathrm{PA}$ co-existing in one patient is an extreme rarely clinical condition. Moreover, the potential PC biomarkers suggested from this analysis are preliminary and need of a robust validation in a large cohort of PC patients.

In conclusion, our differential proteomic analysis highlighted some molecular aspects of PC, which outline the malignant cell metabolic reprogramming, oxidative stress resistance, and increased proliferation. The occurrence of both PC and PA in the same patient allowed us to detect specific protein changes overcoming population variability due to age, sex, genetic background, environmental factors, life styles, concomitant pathological conditions, and pharmacological treatments. Although some deregulated proteins in PC have been also found over- or under-expressed in PA (10), others are peculiar of PC and seem to represent a distinctive molecular signature of $\mathrm{PC}$ with respect to PA. Those proteins exclusively overexpressed in PC may be considered as potential immunohistochemical biomarkers. While UCH-L1 is already a well established PC biomarker, MDH1, CLIC1, and SOD2 might be regarded as candidate biomarkers. Of course, further studies on large populations of PC and PA patients are required to support the use of these proteins as diagnostic tools.

\section{Conflicts of Interest}

The Authors declare that they have no potential conflicts of interest.

\section{Authors' Contributions}

MRM, LG, FC (Federica Ciregia), FC (Filomena Cetani): designed the study, coordinated the research, analyzed data and wrote the manuscript; FC (Filomena Cetani), EP, SB: performed the clinical evaluation of patients; FC (Federica Ciregia), AS, CP: carried out sample preparation and protein separation by electrophoresis and statistical analysis; LZ: carried out western blot analysis and statistical analysis; MR, VC: carried out nanoLC-MS/MS and analyzed MS data. AL, CM helped to draft the manuscript. All Authors read and approved the final version of the manuscript.

\section{References}

1 Walker MD and Silverberg SJ: Primary hyperparathyroidism. Nat Rev Endocrinol 14(2): 115-125, 2018. PMID: 28885621. DOI: $10.1038 /$ nrendo.2017.104

2 Cetani F, Marcocci C, Torregrossa L and Pardi E: Atypical parathyroid adenomas: challenging lesions in the differential diagnosis of endocrine tumors. Endocr Relat Cancer 26(7): R441R464, 2019. PMID: 31085770. DOI: 10.1530/ERC-19-0135

3 Cardoso L, Stevenson M and Thakker RV: Molecular genetics of syndromic and non-syndromic forms of parathyroid carcinoma. Hum Mutat 38(12): 1621-1648, 2017. PMID: 28881068. DOI: 10.1002/humu.23337

4 Cetani F, Pardi E and Marcocci C: Update on parathyroid carcinoma. J Endocrinol Invest 39(6): 595-606, 2016. PMID: 27001435. DOI: 10.1007/s40618-016-0447-3

5 Brewer K, Costa-Guda J and Arnold A: Molecular genetic insights into sporadic primary hyperparathyroidism. Endocr Relat Cancer 26(2): R53-R72, 2019. PMID: 30475215. DOI: 10.1530/ERC-18-0304

6 Costa-Guda J and Arnold A: Genetic and epigenetic changes in sporadic endocrine tumors: parathyroid tumors. Mol Cell Endocrinol 386(1-2): 46-54, 2014. PMID: 24035866. DOI: 10.1016/j.mce.2013.09.005

7 Cetani F, Pardi E, Giovannetti A, Cerrai P, Borsari S, Vignali E, Picone A, Cianferotti L, Miccoli P, Pinchera A and Marcocci C: Six novel MEN1 gene mutations in sporadic parathyroid tumors. Hum Mutat 16(5): 445, 2000. PMID: 11058905. DOI: 10.1002/10981004(200011)16:5<445::AID-HUMU12>3.0.CO;2-6

8 Newey PJ, Nesbit MA, Rimmer AJ, Attar M, Head RT, Christie PT, Gorvin CM, Stechman M, Gregory L, Mihai R, Sadler G, McVean G, Buck D and Thakker RV: Whole-exome sequencing studies of nonhereditary (sporadic) parathyroid adenomas. J Clin Endocrinol Metab 97(10): E1995-E2005, 2012. PMID: 22855342. DOI: $10.1210 /$ jc.2012-2303

9 Cetani F, Pardi E and Marcocci C: Parathyroid carcinoma: a clinical and genetic perspective. Minerva Endocrinol 43(2): 144-155, 2018. PMID: 28949121. DOI: 10.23736/S0391-1977.17.02737-7

10 Giusti L, Cetani F, Ciregia F, Da Valle Y, Donadio E, Giannaccini G, Banti C, Pardi E, Saponaro F, Basolo F, Berti P, Miccoli P, Pinchera A, Marcocci C and Lucacchini A: A proteomic approach to study parathyroid glands. Mol Biosyst 7(3): 687-699, 2011. PMID: 21180715. DOI: 10.1039/c0mb00191k 
11 Arya AK and Sachdeva N: Changes in plasma intact parathyroid hormone levels following 24-hour incubation at room temperature as determined by Roche electrochemiluminescence PTH immunoassay. Clin Lab 60(4): 689-692, 2014. PMID: 24779307. DOI: 10.7754/clin.lab.2013.130419

12 Arya AK, Bhadada SK, Mukherjee S, Singh P, Rana SS, Dahiya D, Sood A, Saikia UN, Prakash M, Bhasin DK, Behera A, Walia R and Bhansali A: Frequency \& predictors of pancreatitis in symptomatic primary hyperparathyroidism. Indian J Med Res 148(6): 721-727, 2018. PMID: 30778006. DOI: 10.4103/ijmr.IJMR_353_16

13 Akpinar G, Kasap M, Canturk NZ, Zulfigarova M, Islek EE, Guler SA, Simsek T and Canturk Z: Proteomics analysis of tissue samples reveals changes in mitochondrial protein levels in parathyroid hyperplasia over adenoma. Cancer Genomics Proteomics 14(3): 197-211, 2017. PMID: 28446534. DOI: $10.21873 / \operatorname{cgp} .20031$

14 Giusti L, Cetani F, Ciregia F, Da Valle Y, Donadio E, Giannaccini G, Banti C, Pardi E, Saponaro F, Basolo F, Berti P, Miccoli P, Pinchera A, Marcocci C and Lucacchini A: A proteomic approach to study parathyroid glands. Mol Biosyst 7(3): 687-699, 2011. PMID: 21180715. DOI: 10.1039/c0mb00191k

15 Ciregia F, Giusti L, Da Valle Y, Donadio E, Consensi A, Giacomelli C, Sernissi F, Scarpellini P, Maggi F, Lucacchini A and Bazzichi L: A multidisciplinary approach to study a couple of monozygotic twins discordant for the chronic fatigue syndrome: a focus on potential salivary biomarkers. J Transl Med 11: 243, 2013. PMID: 24088505. DOI: 10.1186/1479-5876-11-243

16 Erickson LA and Mete O: Immunohistochemistry in diagnostic parathyroid pathology. Endocr Pathol 29(2): 113-129, 2018. PMID: 29626276. DOI: 10.1007/s12022-018-9527-6

17 Fang Y and Shen X: Ubiquitin carboxyl-terminal hydrolases: involvement in cancer progression and clinical implications. Cancer Metastasis Rev 36(4): 669-682, 2017. PMID: 29080080. DOI: $10.1007 / \mathrm{s} 10555-017-9702-0$

18 Hibi K, Liu Q, Beaudry GA, Madden SL, Westra WH, Wehage SL, Yang SC, Heitmiller RF, Bertelsen AH, Sidransky D and Jen $\mathrm{J}$ : Serial analysis of gene expression in non-small cell lung cancer. Cancer Res 58(24): 5690-5694, 1998. PMID: 9865724.

19 Yamazaki T, Hibi K, Takase T, Tezel E, Nakayama H, Kasai Y, Ito K, Akiyama S, Nagasaka T and Nakao A: PGP9.5 as a marker for invasive colorectal cancer. Clin Cancer Res $8(1)$ : 192-195, 2002. PMID: 11801558.

20 Leiblich A, Cross SS, Catto JW, Pesce G, Hamdy FC and Rehman I: Human prostate cancer cells express neuroendocrine cell markers PGP 9.5 and chromogranin A. Prostate 67(16): 1761-1769, 2007. PMID: 17929277. DOI: 10.1002/pros.20654

21 Xiang T, Li L, Yin X, Yuan C, Tan C, Su X, Xiong L, Putti TC, Oberst M, Kelly K, Ren G and Tao Q: The ubiquitin peptidase UCHL1 induces G0/G1 cell cycle arrest and apoptosis through stabilizing p53 and is frequently silenced in breast cancer. PLoS One 7(1): e29783, 2012. PMID: 22279545. DOI: 10.1371/journal. pone.0029783

22 Zhao Y, Lei Y, He SW, Li YQ, Wang YQ, Hong XH, Liang YL, Li JY, Chen Y, Luo WJ, Zhang PP, Yang XJ, He QM, Ma J, Liu $\mathrm{N}$ and Tang LL: Hypermethylation of UCHL1 promotes metastasis of nasopharyngeal carcinoma by suppressing degradation of cortactin (CTTN). Cells 9(3): 559, 2020. PMID: 32120844. DOI: 10.3390/cells9030559

23 Liu S, González-Prieto R, Zhang M, Geurink PP, Kooij R, Iyengar PV, van Dinther M, Bos E, Zhang X, Le Dévédec SE, van de Water B, Koning RI, Zhu HJ, Mesker WE, Vertegaal ACO, Ovaa H, Zhang L, Martens JWM and Ten Dijke P: Deubiquitinase activity profiling identifies UCHL1 as a candidate oncoprotein that promotes TGF $\beta$-induced breast cancer metastasis. Clin Cancer Res 26(6): 1460-1473, 2020. PMID: 31857432. DOI: 10.1158/1078-0432.CCR-19-1373

24 Haven CJ, Howell VM, Eilers PH, Dunne R, Takahashi M, van Puijenbroek M, Furge K, Kievit J, Tan MH, Fleuren GJ, Robinson BG, Delbridge LW, Philips J, Nelson AE, Krause U, Dralle H, Hoang-Vu C, Gimm O, Morreau H, Marsh DJ and Teh BT: Gene expression of parathyroid tumors: molecular subclassification and identification of the potential malignant phenotype. Cancer Res 64(20): 7405-7411, 2004. PMID: 15492263. DOI: 10.1158/0008-5472.CAN-04-2063

25 Adam MA, Untch BR and Olson JA Jr: Parathyroid carcinoma: current understanding and new insights into gene expression and intraoperative parathyroid hormone kinetics. Oncologist 15(1): 6172, 2010. PMID: 20051478. DOI: 10.1634/theoncologist.20090185

26 Howell VM, Gill A, Clarkson A, Nelson AE, Dunne R, Delbridge LW, Robinson BG, Teh BT, Gimm O and Marsh DJ: Accuracy of combined protein gene product 9.5 and parafibromin markers for immunohistochemical diagnosis of parathyroid carcinoma. J Clin Endocrinol Metab 94(2): 434-441, 2009. PMID: 19017757. DOI: 10.1210/jc.2008-1740

27 Kruijff S, Sidhu SB, Sywak MS, Gill AJ and Delbridge LW: Negative parafibromin staining predicts malignant behavior in atypical parathyroid adenomas. Ann Surg Oncol 21(2): 426-433, 2014. PMID: 24081804. DOI: 10.1245/s10434-013-3288-8

28 Truran PP, Johnson SJ, Bliss RD, Lennard TW and Aspinall SR: Parafibromin, galectin-3, PGP9.5, Ki67, and cyclin D1: using an immunohistochemical panel to aid in the diagnosis of parathyroid cancer. World J Surg 38(11): 2845-2854, 2014. PMID: 25002250. DOI: 10.1007/s00268-014-2700-2

29 Kumari N, Chaudhary N, Pradhan R, Agarwal A and Krishnani $\mathrm{N}$ : Role of histological criteria and immunohistochemical markers in predicting risk of malignancy in parathyroid neoplasms. Endocr Pathol 27(2): 87-96, 2016. PMID: 26984237. DOI: $10.1007 / \mathrm{s} 12022-016-9426-7$

30 Agarwal A, Pradhan R, Kumari N, Krishnani N, Shukla P, Gupta SK, Chand G, Mishra A, Agarwal G, Verma AK and Mishra SK: Molecular characteristics of large parathyroid adenomas. World J Surg 40(3): 607-614, 2016. PMID: 26669787. DOI: 10.1007/ s00268-015-3380-2

31 Sharma MC: Annexin A2 (ANX A2): An emerging biomarker and potential therapeutic target for aggressive cancers. Int $\mathbf{J}$ Cancer 144(9): 2074-2081, 2019. PMID: 30125343. DOI: $10.1002 / \mathrm{ijc} .31817$

$32 \mathrm{Hu}$ Y, Zhang X, Cui M, Wang M, Su Z, Liao Q and Zhao Y: Circular RNA profile of parathyroid neoplasms: analysis of coexpression networks of circular RNAs and mRNAs. RNA Biol 16(9): 1228-1236, 2019. PMID: 31213128. DOI: 10.1080/ 15476286.2019 .1622962

33 Jaiswal JK and Nylandsted J: S100 and annexin proteins identify cell membrane damage as the Achilles heel of metastatic cancer cells. Cell Cycle 14(4): 502-509, 2015. PMID: 25565331. DOI: 10.1080/15384101.2014.995495

34 Jaiswal JK, Lauritzen SP, Scheffer L, Sakaguchi M, Bunkenborg J, Simon SM, Kallunki T, Jäättelä M and Nylandsted J: S100A11 is required for efficient plasma membrane repair and survival of 
invasive cancer cells. Nat Commun 5: 3795, 2014. PMID: 24806074. DOI: $10.1038 /$ ncomms4795

35 Pennington KL, Chan TY, Torres MP and Andersen JL: The dynamic and stress-adaptive signaling hub of 14-3-3: emerging mechanisms of regulation and context-dependent protein-protein interactions. Oncogene 37(42): 5587-5604, 2018. PMID: 29915393. DOI: $10.1038 / \mathrm{s} 41388-018-0348-3$

36 Ciregia F, Giusti L, Molinaro A, Niccolai F, Mazzoni MR, Rago $\mathrm{T}$, Tonacchera M, Vitti P, Giannaccini G and Lucacchini A: Proteomic analysis of fine-needle aspiration in differential diagnosis of thyroid nodules. Transl Res 176: 81-94, 2016. PMID: 27172385. DOI: 10.1016/j.trsl.2016.04.004

37 Magnoni R, Palmfeldt J, Hansen J, Christensen JH, Corydon TJ and Bross P: The Hsp60 folding machinery is crucial for manganese superoxide dismutase folding and function. Free Radic Res 48(2): 168-179, 2014. PMID: 24151936. DOI: $10.3109 / 10715762.2013 .858147$

38 Yun CW, Kim HJ, Lim JH and Lee SH: Heat shock proteins: Agents of cancer development and therapeutic targets in anticancer therapy. Cells 9(1): 60, 2019. PMID: 31878360. DOI: $10.3390 /$ cells 9010060

39 Guo J, Li X, Zhang W, Chen Y, Zhu S, Chen L, Xu R, Lv Y, Wu D, Guo M, Liu X, Lu W and Deng H: HSP60-regulated mitochondrial proteostasis and protein translation promote tumor growth of ovarian cancer. Sci Rep 9(1): 12628, 2019. PMID: 31477750. DOI: $10.1038 / \mathrm{s} 41598-019-48992-7$

40 Zhang J, Zhou X, Chang H, Huang X, Guo X, Du X, Tian S, Wang L, Lyv Y, Yuan P and Xing J: Hsp60 exerts a tumor suppressor function by inducing cell differentiation and inhibiting invasion in hepatocellular carcinoma. Oncotarget 7(42): 6897668989, 2016. PMID: 27677587. DOI: 10.18632/oncotarget.12185

41 Park WS, Chung KW, Young MS, Kim SK, Lee YJ and Lee EK: Differential protein expression of lymph node metastases of papillary thyroid carcinoma harboring the BRAF mutation. Anticancer Res 33(10): 4357-4364, 2013. PMID: 24123003.

42 Corrado A, Aceto R, Silvestri R, Dell'Anno I, Ricci B, Miglietta S, Romei C, Giovannoni R, Poliseno L, Evangelista M, Vitiello M, Cipollini M, Garritano S, Giusti L, Zallocco L, Elisei R, Landi S and Gemignani F: Pro64His (rs4644) polymorphism within galectin-3 is a risk factor of differentiated thyroid carcinoma and affects the transcriptome of thyrocytes engineered via CRISPR/Cas9 system. Thyroid 31(7): 1056-1066, 2021. PMID: 33308024. DOI: $10.1089 /$ thy.2020.0366

43 Wulfkuhle JD, Sgroi DC, Krutzsch H, McLean K, McGarvey K, Knowlton M, Chen S, Shu H, Sahin A, Kurek R, Wallwiener D, Merino MJ, Petricoin EF 3rd, Zhao Y and Steeg PS: Proteomics of human breast ductal carcinoma in situ. Cancer Res 62(22): 6740-6749, 2002. PMID: 12438275.
44 Tang HY, Beer LA, Tanyi JL, Zhang R, Liu Q and Speicher DW: Protein isoform-specific validation defines multiple chloride intracellular channel and tropomyosin isoforms as serological biomarkers of ovarian cancer. J Proteomics 89: 165-178, 2013. PMID: 23792823. DOI: 10.1016/j.jprot.2013.06.016

45 Wang L, He S, Tu Y, Ji P, Zong J, Zhang J, Feng F, Zhao J, Zhang $\mathrm{Y}$ and Gao G: Elevated expression of chloride intracellular channel 1 is correlated with poor prognosis in human gliomas. J Exp Clin Cancer Res 31: 44, 2012. PMID: 22578365. DOI: 10.1186/1756-9966-31-44

46 Peretti M, Angelini M, Savalli N, Florio T, Yuspa SH and Mazzanti M: Chloride channels in cancer: Focus on chloride intracellular channel 1 and 4 (CLIC1 AND CLIC4) proteins in tumor development and as novel therapeutic targets. Biochim Biophys Acta 1848(10 Pt B): 2523-2531, 2015. PMID: 25546839. DOI: $10.1016 /$ j.bbamem.2014.12.012

47 Wang YY, Chen J, Liu XM, Zhao R and Zhe H: Nrf2-mediated metabolic reprogramming in cancer. Oxid Med Cell Longev 2018: 9304091, 2018. PMID: 29670683. DOI: 10.1155/ 2018/9304091

48 Kim YS, Gupta Vallur P, Phaëton R, Mythreye K and Hempel $\mathrm{N}$ : Insights into the dichotomous regulation of SOD2 in cancer. Antioxidants (Basel) 6(4): 86, 2017. PMID: 29099803. DOI: 10.3390/antiox6040086

49 Ashtekar A, Huk D, Magner A, La Perle KMD, Boucai L and Kirschner LS: Alterations in Sod2-induced oxidative stress affect endocrine cancer progression. J Clin Endocrinol Metab 103(11): 4135-4145, 2018. PMID: 30165401. DOI: 10.1210/jc.201801039

50 Zhang B, Tornmalm J, Widengren J, Vakifahmetoglu-Norberg H and Norberg E: Characterization of the role of the malate dehydrogenases to lung tumor cell survival. J Cancer $8(11)$ : 2088-2096, 2017. PMID: 28819410. DOI: 10.7150/jca.19373

51 Wang YP, Zhou W, Wang J, Huang X, Zuo Y, Wang TS, Gao X, Xu YY, Zou SW, Liu YB, Cheng JK and Lei QY: Arginine methylation of MDH1 by CARM1 inhibits glutamine metabolism and suppresses pancreatic cancer. Mol Cell 64(4): 673-687, 2016. PMID: 27840030. DOI: 10.1016/j.molcel.2016.09.028

52 Hanse EA, Ruan C, Kachman M, Wang D, Lowman XH and Kelekar A: Cytosolic malate dehydrogenase activity helps support glycolysis in actively proliferating cells and cancer. Oncogene 36(27): 3915-3924, 2017. PMID: 28263970. DOI: 10.1038/onc.2017.36
Received April 24, 2021

Revised September 2, 2021

Accepted September 17, 2021 